Article

\title{
Analysis of Wastewater Generated in Greenhouse Soilless Tomato Cultivation in Central Europe
}

\author{
Artur Mielcarek $^{1}{ }^{1}$, Joanna Rodziewicz ${ }^{1, *}$, Wojciech Janczukowicz ${ }^{1}$ and Artur Dobrowolski ${ }^{2}$ \\ 1 Department of Environment Engineering, Faculty of Environmental Science, University of Warmia and \\ Mazury in Olsztyn, Warszawska 117a, 10-719 Olsztyn, Poland; artur.mielcarek@uwm.edu.pl (A.M.); \\ jawoj@uwm.edu.pl (W.J.) \\ 2 Department of Horticulture, University of Warmia and Mazury in Olsztyn, ul. Prawocheńskiego 21, \\ 10-957 Olsztyn, Poland; artur.dobrowolski@uwm.edu.pl \\ * Correspondence: joanna.rodziewicz@uwm.edu.pl; Tel.: +48-895-245-609
}

Received: 30 September 2019; Accepted: 27 November 2019; Published: 1 December 2019

check for updates

\begin{abstract}
Soilless plantations under cover constitute a significant part of horticulture. This study aimed at determining the qualitative composition of wastewater generated from the soilless cultivation of tomato under cover. This is important for managing the wastewater, which may be recirculated to allow the or employ a partial or complete recovery of minerals. Two plantations located in north-eastern Poland, which differed in the type of substratum (coconut fiber or rockwool), were studied. The generated wastewater was characterized by a low content of organic matter and a high concentration of total nitrogen (TN), total phosphorus (TP), and salinity (EC). Over $99 \%$ of the $\mathrm{TN}$ was constituted by nitrates. The chemical oxygen demand (COD) changed from 50.07 to $75.82 \mathrm{mgO}_{2} \cdot \mathrm{L}^{-1}$ (greenhouse 1), and from 37.35 to $78.12 \mathrm{mgO}_{2} \cdot \mathrm{L}^{-1}$ (greenhouse 2); the content of TN changed from 403.59 to $614.89 \mathrm{mgN} \cdot \mathrm{L}^{-1}$ (greenhouse 1), and from 270.00 to $577.40 \mathrm{mgN} \cdot \mathrm{L}^{-1}$ (greenhouse 2); that of TP changed from 35.44 to $78.00 \mathrm{mgP} \cdot \mathrm{L}^{-1}$ (greenhouse 1), and from 54.10 to $104.00 \mathrm{mgP} \cdot \mathrm{L}^{-1}$ (greenhouse 2); and the EC changed from 3.53 to $6.93 \mathrm{mS} \cdot \mathrm{cm}^{-1}$ (greenhouse 1), and from 4.94 to $6.94 \mathrm{mS} \cdot \mathrm{cm}^{-1}$ (greenhouse 2). No statistically significant correlations were noted between TN and TP, or between TP and EC.
\end{abstract}

Keywords: drainage water; nutrients loss; tomato soilless cultivation; wastewater quality

\section{Introduction}

In addition to providing good quality food, the solutions applied in plant production should ensure that the natural environment is protected. In modern agriculture, the use of mineral fertilizers is common; their inappropriate use, however, poses a serious hazard to the aquatic environment. Soilless cultivations are isolated from the soil, and fertigation (fertilization and irrigation) installations have come into widespread use [1]. This enables the optimization of the obtained yields, through the adjustment of the composition and amount of the nutrient medium to the current needs of crops, taking into account the weather conditions. In view of the need to ensure an optimum amount of nutrients, and to prevent the accumulation of salts in the root zone, these cultivations must be conducted using an excess of the nutrient medium. This usually amounts to $25 \%-45 \%$, which results in the generation of approximately $4.5 \mathrm{~L} \cdot \mathrm{m}^{-2}$ of drainage water with a high concentration of nutrients [2]. We are currently living in a low carbon economy, with a growing awareness of environmental protection and a strengthening of water resource-related legislation, and the need to recover nutrients from wastewater has become apparent [3].

All over the world, the issue of water management in such sites has not been completely resolved. The problem of overflow management should be regarded as very serious and increasing [4]. In Poland, 
almost $100 \%$ of soilless cultivations are operated using open fertilization systems. This means that the excess nutrient medium is discharged directly either into the ground within the greenhouse, or to the surface waters. This practice is common in many countries $[1,4,5]$. In order to protect the environment, various biological and physicochemical methods of wastewater treatment can be used [6]. Conventional treatment generally does not allow for the recovery or the reuse of nutrients, leading to the loss and dilution of important resources [7]. Fertilizer components are thus irretrievably lost. However, wastewater can be a source of valuable commodities, including phosphate, nitrogen, calcium, potassium, and other micro- and macro-elements used in fertilization [3], which can be used in processes such as sorption [8] or ultra- and micro-filtration [9]. With regards to tomato cultivation on mineral wool, the amounts of nitrogen and phosphorus introduced to the environment may amount to $23-245 \mathrm{~kg} \mathrm{~N} \cdot \mathrm{ha}^{-1}$ and 2-54 kg P.ha ${ }^{-1}$ per month, respectively, for a production period of 9-10 months $[1,10]$. Similar losses are noted for other soilless cultivations such as roses or cucumbers. For roses, the amount of nitrogen lost may amount to $2000 \mathrm{~kg} \mathrm{~N} \cdot \mathrm{ha}^{-1}$ in a year, which accounts for $60 \%$ of the amount introduced into the cultivation [11]. While in the fertigation of cucumbers, the amount of nitrogen lost may account for $33 \%-43 \%$ and the amount of phosphorus lost may account for $35 \%-47 \%$ of the load introduced along with the nutrient medium. For phosphorus, this is all the more important, as the non-renewable resources of phosphorus are estimated to only last for the next 50-100 years [12]. The compounds contained in the overflow, while moving throughout the ground, penetrate the groundwater and pollute it. This hinders its use for fertigation purposes and in many other economic sectors, as well as in supplying drinking water $[1,13]$. This has resulted in the need to find the best economic and ecological solutions, enabling a reduction in the amount of biogenic compounds introduced into the environment through drainage water from soilless crop cultivation. To this end, it is first necessary to characterize the quality of the generated overflow, and thus the trends in its management. This will produce the highest environmental and economic benefits, such as a reduction of production costs related to water intake and the purchase of mineral fertilizers, resource recovery, and improved sustainability, by creating a circular economy in soilless tomato cultivation. The aim of the study was to determine the qualitative changes in drainage water (i.e., a specific type of industrial wastewater discharged during soilless tomato cultivation under shelter). The study was conducted at two sites, differing in cultivation area surface and the type of substrate used. It also presents the existing trends in the treatment and/or management of drainage waters.

\section{Materials and Methods}

\subsection{Materials}

The wastewater samples used in the study originated from two greenhouses for soilless tomato cultivation under shelter, located in north-eastern Poland. They were equipped with shading and heat-insulating curtains, and lower, upper, lateral, and vegetation heating. The greenhouses were equipped with weather stations providing current weather data. Despite the common features, the greenhouses involved in the study differed in production scale and type of substrate used (Figure 1).

Greenhouse 1 had an area of approximately $100 \mathrm{~m}^{2}$. As a result of the small production scale, the frequencies and amounts of supplied nutrient medium, as well as its concentration, were selected manually. Water originated from the municipal water supply network. The temperature, humidity, and insolation (shading) inside the tunnel were controlled automatically. The substrate for plant growth was a coconut fibre mat.

Greenhouse 2, with an area of approximately $200,000 \mathrm{~m}^{2}$, was much more automated because of the industrial scale of the production. The greenhouse was equipped with a system to automatically control the temperature, humidity, and insolation (shading). Fertilizers were also dosed automatically. In addition, a computer system controlled the fogging and cooling. The amount and quality of the nutrient medium were regularly controlled by the computer system, and were adjusted to the 
prevailing atmospheric conditions. Water originated from the greenhouses' own underground water intake, and the substrate was a mineral wool mat.

The samples for the analysis were collected on the same day from greenhouses 1 and 2 . At both greenhouses, concentrated nutrient medium solutions were prepared from mineral fertilizers intended for fertigation. The following were used: lime saltpetre, saltpetre, potassium monophosphate, potassium sulphate, magnesium sulphate, iron chelate, micronutrient solution, and nitric and phosphoric acids.

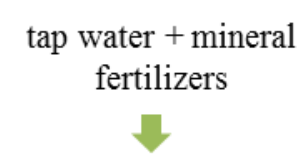

Object 1

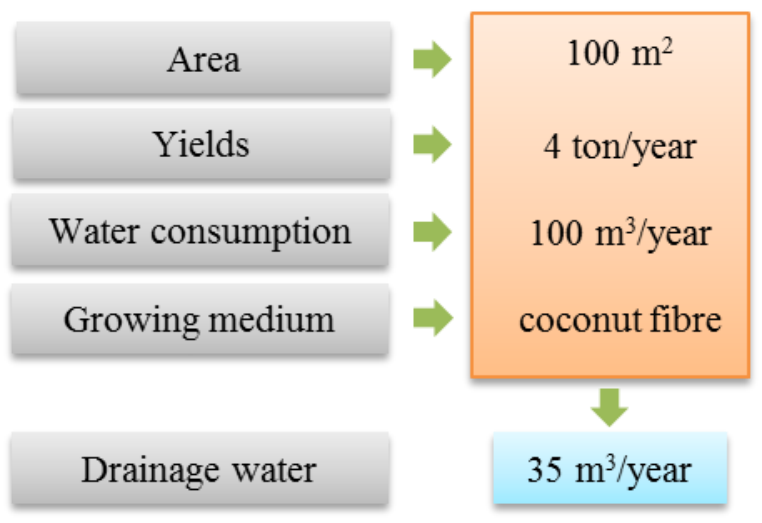

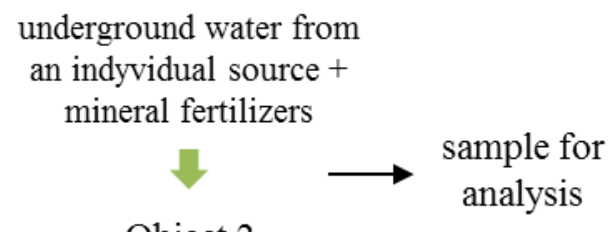

Object 2

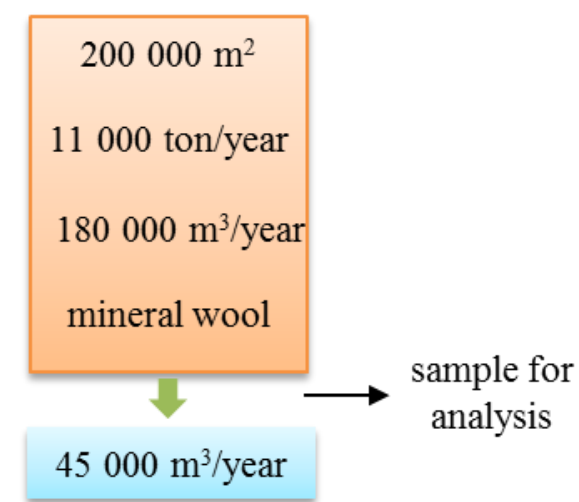

Figure 1. Characteristics of the greenhouses.

\subsection{Analytical Procedures}

Physicochemical analyses were carried out for the pre-prepared nutrient medium supplied for both the root system and for the overflow. Samples for testing were collected monthly from each greenhouse for a period of nine months.

In the study, the following were measured: $\mathrm{pH}$ value and electrical conductivity (EC), using a CP-105 waterproof $\mathrm{pH}$-meter (Elmetron, Poland); total nitrogen (TN), using a TNM-L device (Shimadzu Corporation, Japan; oxidative combustion-chemiluminescence method); total phosphorus (TP; HACH Lange LCK 348-350 method), using the DR5000 HACH Lange Spectrophotometer (Germany); chemical oxygen demand (COD; titrimetric method) [14], using a Gerhardt KI 16 (Germany) laboratory heater; ammonia nitrogen (spectrophotometric method) [15]; and nitrates (spectrophotometric method) [16], using a VWR UV-3100PC Spectrophotometer (China).

\subsection{Statistical Analysis}

A correlation analysis was conducted for the TN, TP, and EC. In order to eliminate the impact of the changes in the nutrient medium parameters during the study, the percentage changes in TN, TP, and EC values between the values noted for the nutrient medium and the overflow were compared. Pearson's correlations were estimated using the correlation matrix in Statistica 12.0. The significance levels of each correlation $(p)$ and the correlation coefficients $(\mathrm{R})$ were calculated. If the probability was less than 0.05 , the correlation was considered significant.

\section{Results and Discussion}

The drainage water generated during soilless tomato cultivation under shelter poses a serious hazard to the aquatic environment, and at the same time, their characteristics prevent the application of 
traditional biological treatment solutions. The quality of wastewater is determined by the composition of the nutrient medium supplied to the root system; the growth phase of plants; the cultivation method, including the type of substrate used; and the weather conditions both inside and outside the greenhouse. Despite fluctuations in the values of basic parameters considered during the design of wastewater treatment systems, their general feature is a high content of oxidised nitrogen compounds (nitrates) and phosphorus (orthophosphates), as well as a very low organic compound content. This prevents the direct application of any processes of biogenic compound removal using heterotrophic microorganisms [2,4].

The COD values during the study for greenhouse 1 were 50.07-75.82 $\mathrm{mg} \mathrm{O}_{2} \cdot \mathrm{L}^{-1}$ (Figure 2) and for greenhouse 2 they were $37.35-78.12 \mathrm{mg} \mathrm{O}_{2} \cdot \mathrm{L}^{-1}$ (Figure 3). They were higher compared with the values in the nutrient medium supplied to the system by an average of $132.1 \pm 41.1 \%$ and $219.6 \pm 92.9 \%$ (for greenhouse 1 and greenhouse 2, respectively). The increase in COD value was most probably caused by the concentration of the nutrient medium due to the transpiration of water by plants, and by organic pollutants in the form of various root exudates and dead plant parts (the root system). The highest COD values noted in the first month of the study (March) could have additionally resulted from the washing out of pollutants from the newly-laid mats, and from the nutrient substances that accumulated in the cubes in which seedlings had been prepared. This is due to the fact that prior to placing the plants in the mats and the commencement of proper fertigation, seed germination occurred in the mineral wool plugs. After approximately two weeks, the seedlings were planted out to cubes of mineral wool. After approximately one month (following the formation of the first inflorescence), they were transferred to the greenhouses under study. During that period, the amount of nutrient medium supplied to the root system in order to induce its expansion was reduced and the mats were saturated with water. These treatments resulted in an increase in the nutrient concentration in the cube with a seedling. After approximately $50 \%$ of the plants at the greenhouse burst into flower, the cubes with seedlings were placed in the pre-prepared holes in the mats.

In the nutrient medium supplied to the plants, the EC values ranged from 2.87 to $3.59 \mathrm{mS} \cdot \mathrm{cm}^{-1}$ (greenhouse 1; Figure 2) and from 2.18 to $3.73 \mathrm{mS} \cdot \mathrm{cm}^{-1}$ (greenhouse 2; Figure 3). The differences resulted from the composition of the supplied solutions, depending on the plant growth phase as well as the plants' demand for water, which was determined by the atmospheric conditions. As a result of the transpiration, the concentration of the nutrient medium and an increase in the concentration of compounds dissolved in the overflow. The EC value for wastewater ranged from 4.40 to $6.93 \mathrm{~m} \mathrm{~S} \cdot \mathrm{cm}^{-1}$ and from 4.94 to $6.94 \mathrm{mS} \cdot \mathrm{cm}^{-1}$, and was higher by an average of $67.1 \pm 19.3 \%$ and by $98.2 \pm 33.9 \%$ compared with the nutrient medium (for greenhouse 1 and greenhouse 2, respectively; Figures 2 and 3).

The levels of TN and TP in the nutrient medium were adjusted, where possible, to the requirements of the plants in a specific growth phase, and to the atmospheric conditions. On the other hand, the concentration of biogenic compounds in the drainage water was determined by the quality of the nutrient medium supplied to the system, its use by plants, and the transpiration rates, and, thus, the concentration of the solution. During the growing period, the percentage of nitrogen and phosphorus content changes in both the dry matter of plants and in the substrate itself, with the changes in the nitrogen content occurring differently to the changes to phosphorus content. Moreover, they are determined by both the substrate used and the nutrient medium composition [17]. In addition, nitrification and denitrification, as well as sorption processes may occur in the substrate, particularly in the initial period of cultivation.

During the study, percentage changes in the TN, TP, and EC concentrations were compared, and the relationships between them were determined. The study demonstrated that only a percentage increase in nitrogen concentration between the inflow and outflow was strongly correlated with the percentage increase in EC (Figure 4). This relationship was noted both in greenhouse 1 ( $p=0.05$, $\mathrm{R}=0.81)$ and in greenhouse $2(p=0.05, \mathrm{R}=0.80)$. No statistically significant correlations were noted between TN and TP, or TP and EC. This is of importance in a situation when overflow recirculation is 
applied. As shown by the study results, the measurement of EC itself is insufficient to properly balance the nutrient medium containing recirculate.

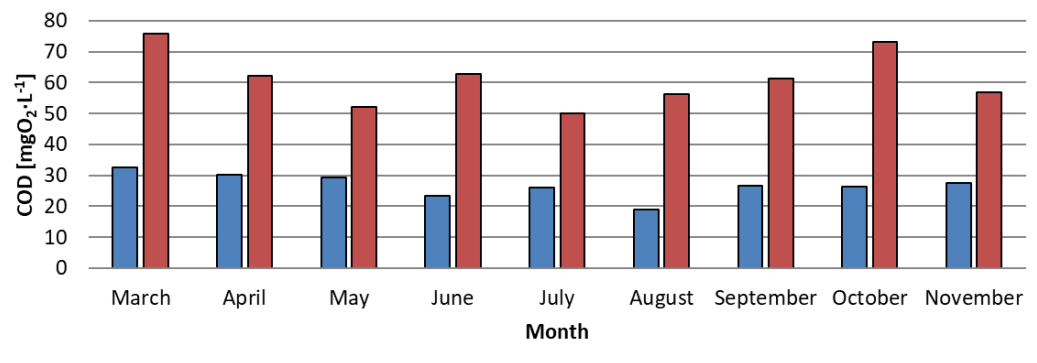

$\square$ Influent $\square$ Effluent

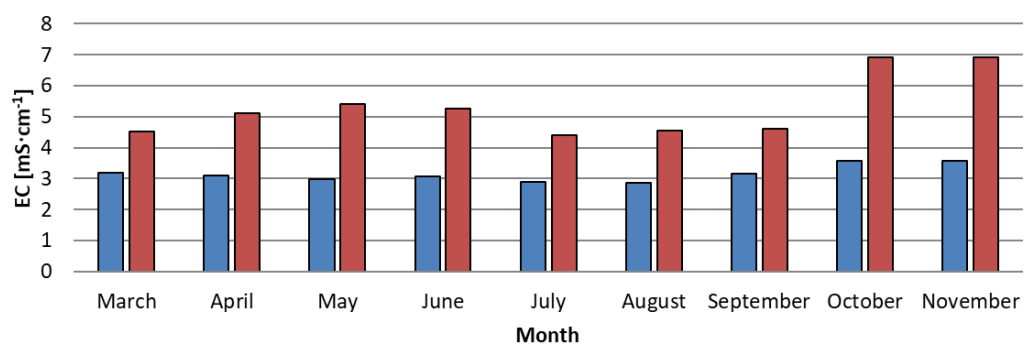

$\square$ Influent $\square$ Effluent
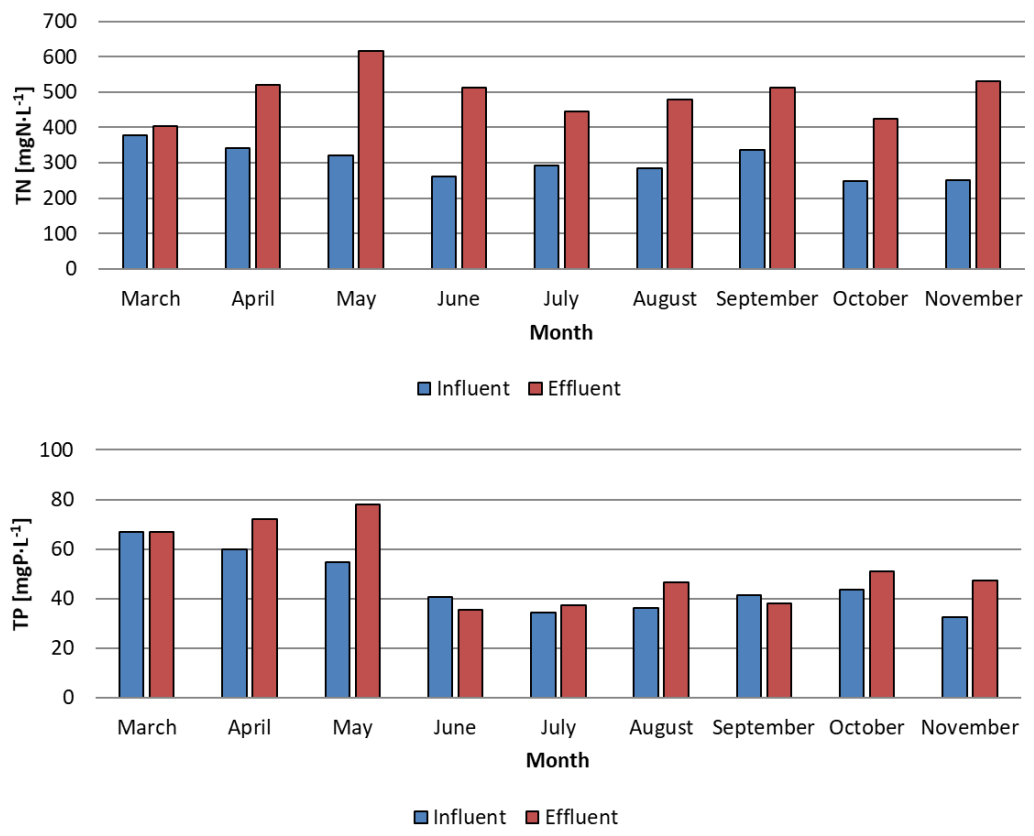

Figure 2. Changed in COD, TN, TP and EC during the study-greenhouse 1.

Nitrates were the main form of nitrogen supplied to the root system. The nitrate concentration was at a trace level, while the ammonia nitrogen concentration ranged from 12.39 to $17.39 \mathrm{mg} N \cdot \mathrm{L}-1$ (greenhouse 1) and from 6.35 to $12.35 \mathrm{mg} \mathrm{N} \cdot \mathrm{L}^{-1}$ (greenhouse 2), and was a result of the presence of ammonia nitrogen in the mineral fertilizers used for the preparation of the nutrient medium. In wastewater, the highest ammonia nitrogen concentrations were noted in the first month of the study, and amounted to 17.81 and $12.30 \mathrm{mg} \mathrm{N} \cdot \mathrm{L}^{-1}$ (for greenhouse 1 and greenhouse 2, respectively). In subsequent months, the ammonia nitrogen concentration did not exceed $1 \mathrm{mg} \mathrm{N} \cdot \mathrm{L}^{-1}$. Only at the end of the growing period (October and November) was there a slight increase in the concentration (up to 3.72 and $2.38 \mathrm{mg} \mathrm{N} \cdot \mathrm{L}^{-1}$ for greenhouse 1 and greenhouse 2, respectively). The initial high 
concentration of ammonium nitrogen most probably resulted from the low level of use by plants (small biomass of the root system and vegetative parts), and from the small number of nitrifying bacteria, which are characterized by a slow growth rate. In the subsequent months, ammonium nitrogen could be fully used up by plants, as well as oxidised in the nitrification process. The slight increase in concentration in the last months was probably caused by a reduction in the rate of plant growth and by the great biomass of the root system, and thus resulted in more intensive processes of decomposition of dead plant tissues.
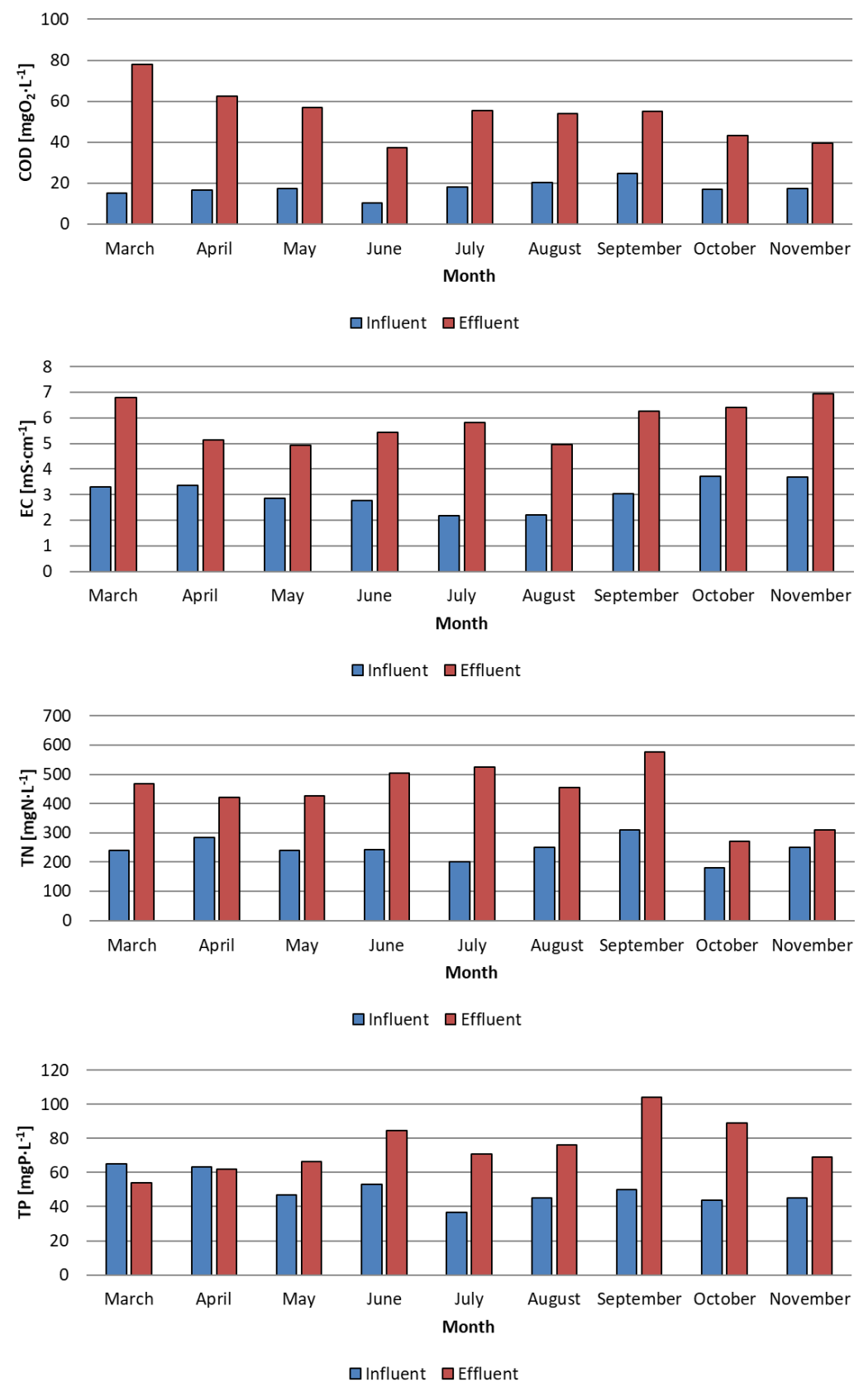

Figure 3. Changes in chemical oxygen demand (COD), total nitrogen (TN), total phosphorus (TP), and salinity (EC) during the study for greenhouse 2.

During the study, in all of the wastewater samples, the TN concentration was higher compared with the supplied nutrient medium, by an average of $66.7 \pm 31.0 \%$ and $80.7 \pm 39.7 \%$, and ranged from 403.59 to $614.89 \mathrm{mg} \mathrm{N} \cdot \mathrm{L}^{-1}$ and from 270.00 to $577.40 \mathrm{mg} \mathrm{N} \cdot \mathrm{L}^{-1}$ for greenhouse 1 and greenhouse 2, respectively (Figures 2 and 3, respectively). Nitrates accounted for over $99 \%$ of the TN in the overflow 
(with the exception of the samples from March; the beginning of the cultivation, approximately 95\%) from both greenhouse 1 and greenhouse 2. As for the TP, the concentration in the wastewater ranged from 35.44 to $78.00 \mathrm{mg} \mathrm{P} \cdot \mathrm{L}^{-1}$ (greenhouse 1), and from 54.10 to $104.00 \mathrm{mg} \mathrm{P.L^{-1 }}$ (greenhouse 2). On average, the TP content was higher by $15.7 \pm 21.1 \%$ and by $56.4 \pm 43.9 \%$ compared with the nutrient medium; however, in certain months, the values for the overflow were lower. In greenhouse 1 , these samples were from March, June and September, while for greenhouse 2, these samples were from March and April (Figures 2 and 3, respectively).
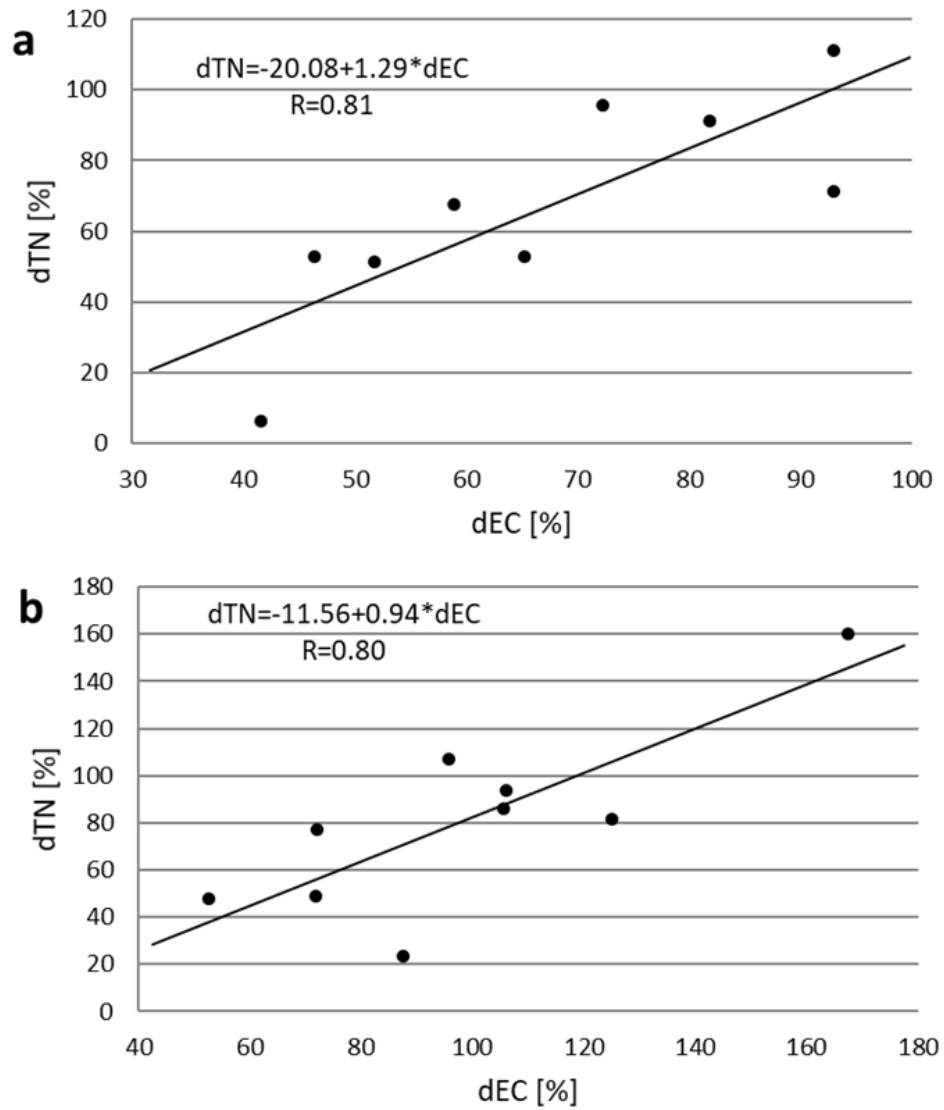

Figure 4. The correlation between the percentage change in the EC and TN values for (a) greenhouse 1 and (b) greenhouse 2.

The obtained results are consistent with those provided in the literature [18]. Breś [10] reported average values for nitrates of $327,378,385,261$, and $162 \mathrm{mg} \mathrm{N} \cdot \mathrm{L}^{-1}$ for the soilless cultivation of Cunero F1 tomatoes, Flavorino F1 tomatoes, Millennium F1 cucumbers, Red Champ roses, and Amaretto Gerbera, respectively. These levels were higher by $114 \% 156 \%, 141 \%, 141 \%$, and $120 \%$, respectively, compared with the nutrient medium supplied to the system. As for TP, they amounted to 37, 38,

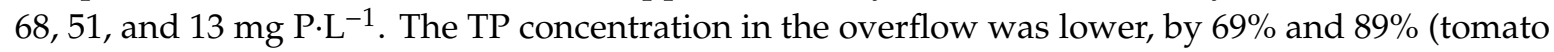
cultivation), and by $81 \%$ and $45 \%$ in rose and Gerbera cultivation, respectively, compared with the nutrient medium. Values higher by an average of $112 \%$ were only noted for wastewater originating from cucumber fertigation. On the other hand, in all of the cultivations, the salinization (expressed as EC) was higher than the solution supplied to the root system by $148 \%, 176 \%, 164 \%, 163 \%$, and

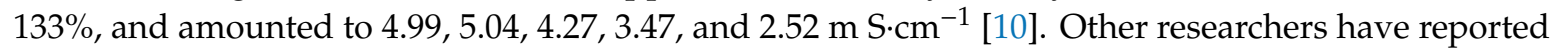
similar results. In a study by Grasselly et al. [18], the nitrate concentration in the overflow from soilless tomato cultivation ranged from 150 to $500 \mathrm{mg} \mathrm{N} \cdot \mathrm{L}^{-1}$. Park et al. [19] reported average values for a mixture of wastewater from tomato and cucumber cultivations at a level of $325 \mathrm{mg} \mathrm{N} \cdot \mathrm{L}^{-1}, 38 \mathrm{mg} \mathrm{P} \cdot \mathrm{L}^{-1}$, an EC of $37.5 \mu \mathrm{mho} \cdot \mathrm{cm}^{-1}$, and a $\mathrm{pH}$ of 6.45 . The authors agree that drainage water from sheltered cultivation is characterized by a low content of organic compounds, combined with a high content of 
easily accessible mineral compounds with a high potential for migration in the natural environment. This is a significant threat to the natural environment.

In order for soilless cultivation under a shelter to be safe for the natural environment, water resource management in such greenhouses should be based on closed cycles with partial pre-treatment and overflow recirculation. However, the water used for irrigation is often characterized by high salt concentrations, including, not only $\mathrm{Na}^{+}$and $\mathrm{Cl}^{-}$, but also $\mathrm{Ca}^{2+}, \mathrm{Mg}^{2+}$, and $\mathrm{SO}_{4}{ }^{2-}$ [20]. Hence, in most cases, the quality of the available irrigation water in terms of mineral composition is incompatible with the application of completely closed systems [21].

In other cases, drainage water should be subjected to desalination, including high-performance denitrification and dephosphatation prior to being introduced into the natural system or sewage system. This is required by both Polish and European Union law [22,23]. For example, in Poland, wastewater discharged from this type of cultivation into the environment should have a total phosphorus concentration of not more than $3 \mathrm{mg} \mathrm{P} \cdot \mathrm{L}^{-1}$, and a total nitrogen of $30 \mathrm{mg} \mathrm{N} \cdot \mathrm{L}^{-1}$ [24]. In order to remove the biogenic compounds from wastewater from soilless cultivations, biological, physical, and chemical methods were applied. As for the methods, based on the activity of plants and microorganisms, there were restrictions associated with atmospheric conditions and the need to use an internal source of organic carbon to ensure an appropriate C:N:P ratio $[2,19,25]$. The application of chemical methods involves the use of reagents, the formation of additional deposits, and, frequently, high investment and operational costs [26-28]. From an economic and environmental perspective, the best solution is the recovery of biogenic compounds (primarily in relation to phosphorus), as well as the use of overflow recirculation, which enables a reduction in the amount of mineral fertilizers and water used. This, however, involves the need to balance the composition of the nutrient medium, which is frequently a difficult problem to solve. In addition, the recirculate needs to be free from pathogens $[29,30]$.

\section{Conclusions}

The aim of the research was to determine the qualitative changes in drainage water from soilless tomato cultivation. The study demonstrated that wastewater from soilless tomato cultivation under shelter, regardless of the production volume or the type of substrate used, is characterized during the entire growing season by a low content of organic compounds, and high levels of TN and TP. In addition, the overflow parameters in relation to the COD, TN, and EC are significantly higher compared with the nutrient medium supplied to the root system. The study demonstrated that only a percentage increase in nitrogen concentration between the inflow and outflow is strongly correlated with the percentage increase in EC. This relationship was noted for both greenhouses. No statistically significant correlations were noted between the TN and TP, or between the TP and EC. This is of importance in a situation when overflow recirculation is applied. As shown by the study results, the measurement of EC itself is insufficient to properly balance the nutrient medium containing recirculate.

Because of the high concentration of nitrates and phosphates combined with small amounts of organic compounds, this type of wastewater requires special treatment processes prior to introduction into the natural environment. In addition, given the high EC of the overflow and the trace content of the reduced nitrogen compounds, a promising solution could be electrobiological reactors with biofilm [31]. Another solution may be semi-open or closed systems with recirculation, and/or the partial treatment of drainage waters and the recovery of nutrients by sorption, microfiltration, and ultrafiltration. These treatments require further research; however, because of the global trend of increases in the surface area of such cultivations and their location in urbanized areas, they need to be introduced as soon as possible. This corresponds to the requirements of the sustainable management of environmental resources and a closed-cycle economy.

Author Contributions: Conceptualization, W.J.; data curation, J.R. and A.D.; formal analysis, A.M.; methodology, J.R. and W.J.; resources, A.D.; supervision, A.M.; visualization, A.M. and J.R.; all authors have read and approved the final manuscript. 
Funding: This study was financed under project no. 18.610.008-300 of the University of Warmia and Mazury in Olsztyn, Poland. The project was financially co-supported by the Minister of Science and Higher Education in the range of the program entitled "Regional Initiative of Excellence" for the years 2019-2022, project no. 010/RID/2018/19, amount of funding 12,000,000 PLN. Artur Mielcarek is also supported by the Foundation for Polish Science (FNP; start 6 August 2016).

Conflicts of Interest: The authors declare no conflict of interest.

\section{References}

1. Kleiber, T. Pollution of the natural environment in intensive cultures under greenhouses. Arch. Environ. Prot. 2012, 38, 45-53. [CrossRef]

2. Prystay, W.; Lo, K.V. Treatment of greenhouse wastewater using constructed wetlands. J. Environ. Sci. Health Part B Pestic. Food Contam. Agric. Wastes 2001, 36, 341-353. [CrossRef] [PubMed]

3. Zacharof, M.P.; Lovitt, R.W. Adding value to wastewater by resource recovery and reformulation as growth media: Current prospects and potential. J. Water Reuse Desalin. 2015, 5, 473-479. [CrossRef]

4. Kumar, R.R.; Cho, J.Y. Reuse of hydroponic waste solution. Environ. Sci. Pollut. Res. 2014, 21, 9569-9577. [CrossRef]

5. Raviv, M.; Lieth, J.H. Soilless Culture: Theory and Practice; Elsevier Science: Amsterdam, The Netherlands, 2008.

6. Metcalf, W.; Eddy, C. Wastewater Engineering: Treatment and Reuse; Tata McGrawHill Publishing Company: New York, NY, USA, 2003.

7. Zacharof, M.P.; Lovitt, R.W. Complex effluent streams as a potential source of volatile fatty acids. Waste Biomass Valoriz. 2013, 4, 557-581. [CrossRef]

8. Jóźwiak, T.; Filipkowska, U.; Szymczyk, P.; Mielcarek, A. Sorption of nutrients (orthophosphate, nitrate III and V) in an equimolar mixture of P-PO4, N-NO2 and N-NO3 using chitosan. Arab. J. Chem. 2016. [CrossRef]

9. Zacharof, M.P.; Lovitt, R.W. The filtration characteristics of anaerobic digester effluents employing cross flow ceramic membrane microfiltration for nutrient recovery. Desalination 2014, 341, 27-37. [CrossRef]

10. Bres, W. Estimation of nutrient losses from open fertigation systems to soil during horticultural plant cultivation. Pol. J. Environ. Stud. 2009, 18, 341-345.

11. De Pascale, S.; Paradiso, R. Water and nutrient uptake of roses growing in two inert media. Acta Hortic. 2001, 548, 631-639. [CrossRef]

12. Cordell, D.; Drangert, J.O.; White, S. The story of phosphorus: Global food security and food for thought. Glob. Environ. Chang. 2009, 19, 292-305. [CrossRef]

13. Komosa, A.; Piróg, J.; Kleiber, T. Changes of macro and micronutrients contents in the root environment of greenhouse tomato grown in fiber wood. Veg. Crop. Res. Bull. 2009, 70, 71-80. [CrossRef]

14. PN-ISO 6060:2006 Water and Wastewater. Research on Oxygen Demand and Organic Carbon Content. Determination of Chemical Oxygen Demand (COD) by Dichromate Method; Polisch Committee for Standarization: Warsaw, Poland, 2006.

15. PN-C-04576-04:1994 Water and Wastewater. Determinations of Nitrogen Compounds. Determination of Ammonium Nitrogen in Water by Direct Nesslerization; Polisch Committee for Standarization: Warsaw, Poland, 1994.

16. PN-82/C-04576.08 Water and Wastewater. Determinations of Nitrogen Compounds. Determination of Nitrate Nitrogen with The Colorimetric Method Using Sodium Salicylate; Polisch Committee for Standarization: Warsaw, Poland, 1982.

17. Da Fonseca, A.F.; Melfi, A.J.; Montes, C.R. Maize growth and changes in soil fertility after irrigation with treated sewage effluent. I. Plant dry matter yield and soil nitrogen and phosphorus availability. Commun. Soil Sci. Plant. Anal. 2005, 36, 1965-1981. [CrossRef]

18. Grasselly, D.; Merlin, G.; Sédilot, C.; Vanel, F.; Dufour, G.; Rosso, L. Denitrification of soilless tomato crops run-off water by horizontal subsurface constructed wetlands. Acta Hortic. 2005, 691, 329-332. [CrossRef]

19. Park, J.B.K.; Craggs, R.J.; Sukias, J.P.S. Treatment of hydroponic wastewater by denitrification filters using plant prunings as the organic carbon source. Bioresour. Technol. 2008, 99, 2711-2716. [CrossRef] [PubMed]

20. Sonneveld, C.; Voogt, W. Plant. Nutrition of Greenhouse Crops; Springer: Basel, Switzerland, 2009; ISBN 9789048125326.

21. Katsoulas, N.; Savvas, D.; Kitta, E.; Bartzanas, T.; Kittas, C. Extension and evaluation of a model for automatic drainage solution management in tomato crops grown in semi-closed hydroponic systems. Comput. Electron. Agric. 2015, 113, 61-71. [CrossRef] 
22. Commission Of The European Communities. Directive of the European Parliament and of the Council Establishing a Framework for the Protection of Soil and Amending Directive 2004/35/EC, EUR-Lex. 2004.

23. Commission Of The European Communities. Directive 2000/60/EC of the European Parliament and of the Council of 23 October 2000 Establishing a Framework for Community Action in the Field of Water Policy, EUR-Lex. 2000.

24. Dz.U. 2019 poz. 1311. Regulation of the Minister of Maritime Economy and Inland Navigation of 12 July 2019 on Substances Particularly Harmful to the Aquatic Environment and Conditions to be Met when Introducing Sewage into Waters or into the Ground, ISAP. 2019.

25. Gagnon, V.; Maltais-Landry, G.; Puigagut, J.; Chazarenc, F.; Brisson, J. Treatment of hydroponics wastewater using constructed wetlands in winter conditions. Water Air Soil Pollut. 2010, 212, 483-490. [CrossRef]

26. Jóźwiak, T.; Mielcarek, A.; Janczukowicz, W.; Rodziewicz, J.; Majkowska-Gadomska, J.; Chojnowska, M. Hydrogel chitosan sorbent application for nutrient removal from soilless plant cultivation wastewater. Environ. Sci. Pollut. Res. 2018, 1-14. [CrossRef]

27. Dunets, C.S.; Zheng, Y. Removal of phosphate from greenhouse wastewater using hydrated lime. Environ. Technol. 2014, 35, 2852-2862. [CrossRef]

28. Koide, S.; Satta, N. Separation Performance of Ion-exchange Membranes for Electrolytes in Drainage Nutrient Solutions subjected to Electrodialysis. Biosyst. Eng. 2004, 87, 89-97. [CrossRef]

29. Gruyer, N.; Dorais, M.; Zagury, G.J.; Alsanius, B.W. Removal of plant pathogens from recycled greenhouse wastewater using constructed wetlands. Agric. Water Manag. 2013, 117, 153-158. [CrossRef]

30. Raudales, R.E.; Fisher, P.R.; Hall, C.R. The cost of irrigation sources and water treatment in greenhouse production. Irrig. Sci. 2017, 35, 43-54. [CrossRef]

31. Rodziewicz, J.; Mielcarek, A.; Janczukowicz, W.; Jóźwiak, T.; Struk-Sokołowska, J.; Bryszewski, K. The share of electrochemical reduction, hydrogenotrophic and heterotrophic denitrification in nitrogen removal in rotating electrobiological contactor (REBC) treating wastewater from soilless cultivation systems. Sci. Total Environ. 2019, 683, 21-28. [CrossRef] [PubMed]

(C) 2019 by the authors. Licensee MDPI, Basel, Switzerland. This article is an open access article distributed under the terms and conditions of the Creative Commons Attribution (CC BY) license (http://creativecommons.org/licenses/by/4.0/). 